\title{
MRI structural findings in schizophrenia
}

\section{Andrew R Gilbert e Matcheri S Keshavan}

\author{
Western Psychiatric Institute and Clinic. Pittsburgh, PA, EUA
}

\section{Introduction}

Described as "dementia praecox" by Emil Kraepelin in the early 1900's, schizophrenia was considered a brain disease at that time. ${ }^{1}$ It was predicted that the future would bring investigative techniques that would enable scientists to better understand the neuropathology of the illness. As we enter the $21^{\text {st }}$ century, the predictions of Kraepelin and his contemporaries have become real, as MRI and more sophisticated neuroimaging techniques have emerged, unveiling many structural abnormalities that are best elucidated through in vivo neuroimaging.

Neuroimaging allows for the in vivo measurement of brain regions without the potential confounds of fixation, and other sources of artifact that can influence postmortem examination of brain tissue. Furthermore, neuroimaging can be used to study first-episode patients, as well as the high-risk relatives of patients, thus understanding the biology of the illness without the potential confounding effects of age, prior treatment and illness chronicity. ${ }^{2}$

Imaging studies have consistently revealed differences between specific brain regions in schizophrenia patients compared to controls. ${ }^{3,4}$ Since the 1970 's, many imaging studies have provided strong evidence that schizophrenia is a neuropathological disease process and may be associated with abnormal neurodevelopment. The brain regions found to be abnormal in schizophrenia patients may comprise brain circuits and pathways that contribute to positive and negative symptoms and executive function déficits. ${ }^{6-8}$ Using MRI, our laboratory has discovered abnormal brain regions in chronic and treated schizophrenia patients, treatment-naïve, firstepisode schizophrenia patients, and the high-risk offspring of schizophrenia patients. In this paper we will provide an overview of our findings and those of other researchers and critically discuss these findings in the context of the vast emerging literature.

\section{Ventricles}

Since 1976, many studies have consistently revealed enlarged lateral ventricular volumes in schizophrenia patients as compared to controls; in fact, this may be the most replicated finding in schizophrenia research. ${ }^{3,49-13}$ The significance of enlarged ventricular volume remains to be understood, as this condition also occurs in hydrocephalus, Alzheimer's Disease, and Huntington's Chorea. Few studies have clarified whether the reduction in ventricular volume is independent of or secondary to tissue loss in surrounding brain regions. Our laboratory recently found reduced thalamic volumes in firstepisode schizophrenia patients, ${ }^{5}$ which did not correlate with lateral or third ventricular volumes in these patients. This finding may suggest that the ventricular and surrounding tissue volume reductions are independent of each other. However, a more thorough analysis of this relationship needs to be explored.

\section{Basal ganglia}

Several studies have reported reduced basal ganglia volumes in schizophrenia patients. ${ }^{14-18}$ It has been postulated that abnormal basal ganglia volumes may explain the abnormal involuntary movements and, possibly, the cognitive dysfunction seen in schizophrenia. The majority of neuroimaging studies measuring basal ganglia volume have examined the brains of chronic, treated schizophrenia patients. We have conducted a morphometric MRI study in a series of first-episode, neuroleptic-naïve schizophrenia patients; we found volume reductions in the left, right, and total caudate nuclei. ${ }^{19}$ Interestingly, in a previous study, we found that caudate volumes increased from baseline, following treatment with conventional antipsychotic medications. ${ }^{20}$ Reduced striatal volumes in treatment-naïve patients have been replicated in other studies, as well as increased caudate size following neuroleptic treatment. ${ }^{21,22}$

\section{Thalamus}

Recently, there has been increasing interest in examining the role of the thalamus in schizophrenia. A vital relay station to the cortex, the thalamus has connections with multiple sensory pathways in the brain. Furthermore, post-mortem studies have consistently revealed reduced thalamic volumes and, as mentioned prior in this paper, the reduction in ventricular volumes in schizophrenia has been postulated to be secondary to surrounding tissue loss. Early studies revealed a combination of findings, including reduced and normal thalamic volumes; however, the majority of these studies examined chronic, treated patients. ${ }^{3,23}$ We found reduced thalamic volumes in treatment-naïve, first-episode schizophrenia patients as well as reductions in regions of the 
thalamus that grossly reflect individual thalamic nuclei, such as the dorsomedial nucleus and pulvinar.* Our total thalamic volume findings are consistent with other studies of early episode and neuroleptic-naïve patients. Few studies, however, have examined the volume of individual thalamic nuclei because current MRI magnets are not powerful enough to delineate these structures. The thalamus is a mosaic of subnuclei, with individual and shared cortical and subcortical connections. Measurement of total thalamic volume is important, but may neglect the regional differences within the thalamus that may contribute to the illness. We are currently measuring thalamic volumes and thalamic subdivision volumes in the young highrisk relatives of schizophrenia patients (i.e. offspring, siblings) to explore the potential neurodevelopmental role of the thalamus in the pathogenesis of schizophrenia.

\section{Frontal lobe}

Due to the cognitive and behavioral deficits characteristic of schizophrenia, prefrontal cortical morphology has been an area of interest in schizophrenia research. Although the frontal lobe is a highly complex conglomeration of several substructures, many studies have measured total frontal lobe volume and reported volume reductions. ${ }^{25}$ Few studies, however, have measured subregions of the prefrontal cortex. Recently, reductions in dorsolateral and orbitofrontal patients have been reported. ${ }^{26}$ There has also been recent interest in measuring components of the heteromodal association cortex (HASC) in schizophrenia; this system is comprised of the planum temporale (PT), dorsolateral prefrontal cortex (DLPFC), Broca's area, and the inferior parietal lobule (IPL). ${ }^{27,29}$ Using cortical sub-parcellation and cortical "paint" techniques, ${ }^{30} \mathrm{a}$ few laboratories have reported right and left inferior prefrontal cortical volume deficits as well as a trend for left DLPFC volume reduction. ${ }^{30,27,28}$ Due to the small size of frontal subregions, replications of abnormal morphological findings are warranted. Furthermore, future analysis of subregions with higher power MRI may better depict subtle differences that current imaging is unable to measure.

\section{Temporal lobe}

Associated with auditory and language processing, and having many limbic connections, the temporal lobe may play a significant role in schizophrenia. Many studies have measured whole temporal lobe volumes as well as neocortical temporal lobe and medial temporal lobe volumes. The majority of MRI studies have found smaller whole temporal lobe volume in schizophrenia. ${ }^{17,23,31,32}$ As with the thalamus, total temporal lobe volume measurements are important but may neglect the potentially significant subdivisional volumetric differences. The medial temporal lobe is composed of the amygdala-hippocampal complex and the parahippocampal gyrus. Most studies have measured amygdala-hippocampal volumes together because they are too difficult to delineate separately. The majority of studies have reported reduced amygdala-hippocampal complex volumes in both chronic and first-episode patients. ${ }^{33-35}$ Reduced parahippocampal gyrus volumes have also been reported. ${ }^{36}$ The neocortical temporal lobe is composed of the superior temporal gyrus (STG) and the planum temporale (PT). Several MRI studies have reported reduced volumes in left STG. ${ }^{31,37}$ Furthermore, reduced total STG volumes have been described in first episode schizophrenia patients. ${ }^{35,38}$ Our laboratory has found similar left STG volume reductions in first episode schizophrenia patients. Interestingly, following one year of neuroleptic treatment, the STG volumes were reversed. ${ }^{39}$ Consistent with other studies, our laboratory has also found reduced hippocampal volume in schizophrenia patients as well as in the at-risk relatives of schizophrenia patients. ${ }^{40,41}$

\section{Cerebellum}

Recently, there has been increased interest in examining the role of the cerebellum in the pathogenesis of schizophrenia. The cortical-cerebellar-thalamic-cortical circuit (CCTCC) has been implicated as a potential contributor to the motor and cognitive dysfunction seen in schizophrenia. ${ }^{7}$ MRI studies have reported both enlarged and reduced cerebellar volumes in schizophrenia patients. ${ }^{23,24}$ Our laboratory found reduced cerebellar and vermal volumes in schizophrenia patients compared to controls. ${ }^{42}$ We are currently measuring specific cerebellar regions in both first-episode schizophrenia patients as well as the high-risk offspring of schizophrenia patients.

\section{Corpus collosum}

The corpus callosum (CC) is the major commissural pathway between the cerebral hemispheres and may play an important role in human behavior and neuropsychiatric disorders. Several studies have revealed variable results in measurements of the $\mathrm{CC}$ in schizophrenia, which may reflect effects of gender, illness chronicity, and neuroleptic exposure. ${ }^{43-45}$ Our laboratory recently measured CC volumes in first-episode schizophrenia patients. Consistent with a recent shape analysis study of CC volumes, we found that the size of the $\mathrm{CC}$ was reduced in firstepisode patients compared to both psychotic and normal controls. ${ }^{46} \mathrm{We}$ also found these patients to have reduced volumes in regions of the corpus callosum, including the anterior genu, anterior body, isthmus, and anterior splenium. Furthermore, the normal age-related increase in size in CC volumes was absent in the first-episode schizophrenia patients, suggesting abnormal CC neurodevelopment in schizophrenia.

\section{Future studies}

MRI has been a valuable tool in the study of the pathogenesis and pathophysiology of schizophrenia. MRI's capacity to measure brain regions in a non-invasive, in vivo approach, has allowed for the study of chronic, treated, treatment-naïve, early episode, and offspring of schizophrenia patients. As we have revealed in this paper, many important differences between schizophrenia patients and controls have emerged. The abnormal brain regions are components of brain circuitry that may be altered in schizophrenia. For example, the reports of reduced prefrontal, basal ganglia, cerebellar and 
thalamic volumes may suggest that there is abnormal corticalstriatal-thalamic-cerebellar activity in schizophrenia. Our laboratory has revealed that these findings are seen in treatment-naive, first-episode patients, which may implicate this circuit in the development of the illness. We are currently measuring these brain regions in the high-risk relatives of patients to better understand the pathogenesis of the illness. As reported in this paper, total regional measurements are important but can minimize the significant sub-regional differences that may be present in the illness. For example, the thalamus is composed of several nuclei that have individual connections and functions. Unfortunately, current MRI technology does not allow for the delineation of these specific nuclei and, therefore, we must devise alternative and less sensitive approaches towards their measurement. We predict that higher resolution imaging will soon emerge and allow for the more detailed analysis that is needed. Approaches to analyze MRI images are also likely to become more sophisticated, with the use of global image averaging and voxel based morphometric approaches..$^{23} \mathrm{We}$ also predict that the near future will bring more advanced imaging techniques to allow for the measurement of specific circuits. For example, our laboratory is currently employing diffusion tensor imaging (DTI) to measure the integrity of white matter tracts within the brains of schizophrenia patients. DTI allows the use of MRI regional measurements as a guide to examine the circuits that these regions compose; in a sense, a sophisticated "connect the dots" approach.

What is the meaning of volumetric differences in patients with schizophrenia? Does reduced volume mean reduced activity? It is important to note that MRI regional measurements do not provide information regarding activity. Brain activity is far too complex to be influenced and understood by volume alone. MRI studies can be used as a guide to further examine the circuits that these regions compose as well as to measure their activity using more sophisticated functional imaging technology.

This work was supported in part by NIMH grants MH45203, 01180, and 45156 (Matcheri S Keshavan) and GCRC grant \#M01 RR00056.

\section{References}

1. Kraepelin E. Dementia praecox. New York: Churchill Livingston Inc.; 1919/1971.

2. Keshavan MS, Schooler NR: First-episode studies in schizophrenia: criteria and characterization. Schizophr Bull 1992;18:491-513.

3. Andreasen NC, Ehrhardt JC, Swayze VW, Alliger RJ, Yuh WT, Cohen G, et al. Magnetic resonance imaging of the brain in schizophrenia. The pathophysiological significance of structural abnormalities. Arch Gen Psychiatry 1990;43:136-44.

4. Corey-Bloom J, Jernigan T, Archibald S, Harris MJ, Jeste DV. Quantitative magnetic resonance imaging of the brain in late-life schizophrenia. Am J Psychiatry 1995;152:447-9.

5. Gilbert AR, Rosenberg DR, Harenski K, Spencer S, Sweeney JA, Keshavan MS. Thalamic volumes in first-episode schizophrenia patients. Am J Psychiatry 2001;158: 618-24.

6. Weinberger DR. Implications of normal brain development for the pathogenesis of schizophrenia. Arch Gen Psychiatry 1987;44:660-9.

7. Murray RM, Lewis SW. Is schizophrenia a neurodevelopmental disorder? Br Med J 1987;295:681-2.

8. Andreasen NC. A unitary model of schizophrenia. Arch Gen Psychiatry 1999;56:781-7.

9. Johnstone EC, Crow TJ, Frith CD, Husband J, Kreel L. Cerebral ventricular size and cognitive impairment in chronic schizophrenia. Lancet 1976;2:924-6.

10. Johnstone EC, Owens DG, Crow TJ, Frith CD, Alexandropolis K, Bydder G, et al. Temporal lobe structure as determined by nuclear magnetic resonance schizophrenia and bipolar affective disorder. J Neurol Neurosurg Psychiatry 1989;52:736-41.

11. Buchsbaum MS, Yang S, Hazlett E, Siegel BV, Germans M, Haznedar M, et al. Ventricular volume and asymmetry in schizotypical personality disorder and schizophrenia assessed with magnetic resonance imaging. Schizophr Res 1997;27:45-53.
12. Lim KO, Tew W, Kushner M, Chow K, Matsumoto B, De Lisi LE. Cortical gray matter volume deficit in patients with firstepisode schizophrenia. Am J Psychiatry 1996;153:1548-53.

13. Gur RE, Mozley PD, Shtasel DL, Cannon TD, Gallacher F, Turetsky B, et al. Clinical subtypes of schizophrenia: differences in brain and CSF volume. Am J Psychiatry 1994;151:343-50.

14. Breier A, Buchanan RW, Elkashef A, Munson RC, Kirkpatrick B, Gellad F. Brain morphology and schizophrenia. A magnetic resonance imaging study of limbic, prefrontal cortex, and caudate structures. Arch Gen Psychiatry 1992;49:921-6.

15. Swayze VW, Andreasen NC, Alliger RJ, Yuh WT, Ehrhardt JC. Subcortical and temporal structures in affective disorder and schizophrenia: a magnetic resonance imaging study. Biol Psychiatry 1992;31:221-40.

16. Jernigan TL, Zisook S, Heaton RK, Moranville JT, Hesselink JR, Braff DL, et al. Magnetic resonance imaging abnormalities in lenticular nuclei and cerebral cortex in schizophrenia. Arch Gen Psychiatry 1991;48:881-90.

17. DeLisi LE, Hoff AL, Schwartz JE, Shields GW, Halthore SN, Gupta SM, et al. Brain morphology in first-episode schizophreniclike psychotic patients: a quantitative magnetic resonance imaging study. Biol Psychiatry 1991;29:159-75.

18. Frazier JA, Giedd JN, Hamburger SD, Albus KE, Kaysen D, Vaituzis $\mathrm{AC}$, et al. Brain anatomic magnetic resonance imaging in childhood-onset schizophrenia. Arch Gen Psychiatry 1996;53:617-24.

19. Keshavan MS, Rosenberg D, Sweeney JA, Pettegrew JW. Decreased caudate volume in neuroleptic-naïve psychotic patients. Am J Psychiatry 1998;155:774-8.

20. Keshavan MS, Bagwell WW, Haas GL, Sweeney JA, Schooler NK, Pettegrew JW. Changes in caudate volume with neuroleptic treatment [letter]. Lancet 1994;344:1434. 
21. Shihabudin L, Buchsbaum MS, Hazlett EA, Haznedar MM, Harvey PD, Newman A, et al. Dorsal striatal size, shape, and metabolic rate in never-medicated and previously medicated schizophrenics performing a verbal learning task. Arch Gen Psychiatry 1998;55:235-43

22. Chakos MH, Lieberman JA, Bilder RM, Borenstein M, Lerner G, Bogerts B, et al. Increase in caudate nuclei volumes of firstepisode schizophrenic patients taking antipsychotic drugs. Am J Psychiatry 1994;151:1430-6.

23. Andreasen NC, Flashman L, Flaum M, Arndt S, Swayze V, O'Leary DS, et al. Regional brain abnormalities in schizophrenia measured with magnetic resonance imaging. JAMA 1994;272:1763-9.

24. Flaum M, Swayze VW, O'Leary DS, Yuh WT, Ehrhardt JC, Arndt SV, et al. Effects of diagnosis, laterality, and gender on brain morphology in schizohprenia. Am $J$ Psychiatry 1995; 152:704-14.

25. Wible CG, Shenton ME, Hokama G, Kikinis R, Jolesz FA, Metcalf $\mathrm{D}$, et al. Prefrontal cortiex and schizophrenia. A quantitative magnetic resonance imaging study. Arch Gen Psychiatry 1995;52:279-88.

26. Goldstein JM, Goodman JM, Seidman LJ, Kennedy DN, Makris $\mathrm{N}$, Lee $\mathrm{H}$, et al. Cortical abnormalities in schizophrenia identified by structural magnetic resonance imaging. Arch Gen Psychiatry 1999;56:537-47

27. Pearlson GD, March L. Structural brain imaging in schizophrenia: a selective review. Biol Psychiatry 1999;46:627-49.

28. Honeycutt NA, Musick A, Barta PE, Pearlson GD. Measurement of the planum temporale (PT) on magnetic resonance imaging scans: temporal PT alone and with parietal extension. Psychiatry Res 2000;10:103-16.

29. Mesulam MM. Large-scale neurocognitive networks and distributed processing for attention, language and memory. Ann Neurol 1990;28:597-613.

30. Ross CA, Pearlson GD. Schizophrenia, the heteromodal association neocortex and development: potential for a neurogenetic approach. Trends Neurosci 1996;19:171-6.

31. Barta PE, Pearlson GD, Powers RE, Richards SS, Tune LE. Auditory hallucinations and smaller superior temporal gyral volume in schizophrenia. Am J Psychiatry 1990;147:1457-62.

32. Gur RE, Cowell P, Turetsky BI, Gallacher F, Cannon T, Bilker W, et al. A follow-up magnetic resonance imaging study of schizophrenia. Relationship of neuroanatomical changes to clinical and neurobehavioral measures. Arch Gen Psychiatry 1998;55:145-52.

33. Bogerts B, Ashtari M, Degreef G, Alvir JM, Bilder RM, Lieberman JA. Reduced temporal limbic structure volumes on magnetic resonance images in first episode schizophrenia. Psychiatry Res 1990;35: 1-13
34. Copolov D, Velakoulis D, McGorry P, Carina Mallard, Yung A, Rees S, et al. Neurobiological findings in early phase schizophrenia. Brain Res Rev 2000;31:157-65.

35. Velakoulis D, Pantelis C, McGorry PD, Dudgeon P, Brewer W, Cook M, et al. Hippocampal volume in first-episode psychoses and chronic schizophrenia: a high-resolution magnetic resonance imaging study. Arch Gen Psychiatry 1999;56:133-41.

36. Kawasaki Y, Maeda Y, Urata K, Higashima M, Yamaguchi N, Suzuki M, et al. A quantitative magnetic resonance imaging study of patients with schizophrenia. Eur Arch Psychiatry 1993;242:268-72.

37. Shenton ME, Kikinis R, Jolesz FA, Pollack SD, LeMay M, Wible $\mathrm{CG}$, et al. Abnormalities of the left temporal lobe and thought disorder in schizophrenia. A quantitative magnetic resonance imaging study. N Eng J Med 1992;327:604-12.

38. Hirayasu Y, Shenton ME, Salisbury DF, Dickey CC, Fisher IA, Mazzoni P, et al. Lower left temporal lobe MRI volumes in patients with first-episode schizophrenia compared with psychotic patients with first-episode affective disorder and normal subjects. Am J Psychiatry 1998;155:1348-91.

39. Keshavan MS, Haas GL, Kahn CE, Aguilar E, Dick EL, Schooler NK, et al. Superior temporal gyrus and the course of early schizophrenia: progressive, static, or reversible? J Psychiatr Res 1998;32:161-7.

40. Keshavan MS, Sharma T. High risk research in schizophrenia. Schizophrenia Monitor 1997;7:1-5.

41. Lawrie SM, Whalley H, Kestelman JN, Abukmeil SS, Byrne M, Hodges A, et al. Magnetic resonance imaging of brain in people at high risk of developing schizophrenia. Lancet 1999;353:30-3.

42. Narayan CR, Bagwell WW, Haas GL, Sweeney JA, Schooler NR, Pettegrew JW, et al. Cerebellar and vermal volume in first-break schizophrenia. Schizophrenia Res 1995;15:86-7.

43. Nasrallah HA, Andreasen NC, Coffman JA, Olson SC, Dunn VD, Ehrhardt JC, et al. A controlled magnetic resonance imaging study of corpus callosum thickness in schizophrenia. Biol Psychiatry 1986;21:274-82.

44. Hauser P, Dauphinais ID, Berrettini W, DeLisi LE, Gelernter J, Post RM, et al. Corpus callosum dimensions measured by magnetic resonance imaging in bipolar affective disorder and schizophrenia. Biol Psychiatry 1989;26:659-68.

45. Uematsu M, Kaiya H. Midsagittal cortical pathomorphology of schizophrenia: a magnetic resonance imaging study. Psychiatry Res 1989;30:11-20.

46. Dequardo JR, Keshavan MS, Bookstein FL, Bagwell WW, Green WD, Sweeney JA, et al. Landmark-based morphometric analysis of first-episode schizohprenia. Biol Psychiatry 1999;45:1321-8. 